\title{
Variance Estimation Using Quartiles and their Functions of an Auxiliary Variable
}

\author{
J. Subramani", G. Kumarapandiyan \\ Department of Statistics, Ramanujan School of Mathematical Sciences, Pondicherry University, R V Nagar, Kalapet, Puducherry, 605014,
} India

\begin{abstract}
In this paper we have proposed a class of modified ratio type variance estimators for estimation of population variance of the study variable using Quartiles and their functions of the auxiliary variable are known. The biases and mean squared errors of the proposed estimators are obtained and also derived the conditions for which the proposed estimators perform better than the traditional rat io type variance estimator and existing modified ratio type variance estimators. Further we have compared the proposed estimators with that of traditional ratio type variance estimator and existing modified ratio type variance estimators for certa in known populations. From the numerical study it is observed that the proposed estimators perform better than the traditional ratio type variance estimator and existing modified ratio type variance estimators.
\end{abstract}

Keywords Inter-Quartile Range, Natural Populations, Simple Random Sampling, Semi-Quartile Average, Semi-Quartile Range

\section{Introduction}

Consider a finite population $U=\left\{U_{1}, U_{2}, \ldots, U_{N}\right\}$ of $N$ distinct and identifiable units. Let $Y$ be a real variable with value $Y_{i}$ measured on $U_{i}, i=1,2,3, \ldots, N$ giving a vector $Y=\left\{Y_{1}, Y_{2}, \ldots, Y_{N}\right\}$. The problem is to estimate the populations mean $\overline{\mathrm{Y}}=\frac{1}{\mathrm{~N}} \sum_{\mathrm{i}=1}^{\mathrm{N}} \mathrm{Y}_{\mathrm{i}}$ or population variance $S_{y}^{2}=\frac{1}{(N-1)} \sum_{i=1}^{N}\left(Y_{i}-\bar{Y}\right)^{2}$ on the basis of a random sample selected from the population U. Estimating the finite population variance has great significance in various fields such as Industry, Agriculture, Medical and Biological Sciences. For example in matters of health, variations in body temperature, pulse beat and blood pressure are the bas ic guides to diagnos is where prescribed treatment is designed to control their variation. In this paper we intend to suggest some estimators for population variance. When there is no additional information on the auxiliary variable available, the simplest estimator of population variance is the simple random sample variance without replacement. It is common practice to use the auxiliary variable for improving the precision of the estimate of a parameter. In this paper, we consider the auxiliary information to improve the efficiency of the estimation of population variance $\mathrm{S}_{\mathrm{y}}^{2}=\frac{1}{(\mathrm{~N}-1)} \sum_{\mathrm{i}=1}^{\mathrm{N}}\left(\mathrm{Y}_{\mathrm{i}}-\overline{\mathrm{Y}}\right)^{2}$ in simple random sampling. When the information on an auxiliary variable $\mathrm{X}$ is known, a number of estimators such as ratio, product and linear regression estimators are proposed in the literature.

Corresponding Author:

drjsubramani@yahoo.co.in(J. Subramani)

Published online at http://journal.sapub.org/statistics

Copyright (C) 2012 Scientific \& Academic Publishing. All Rights Reserved
When the correlation between the study variable and the auxiliary variable is positive, ratio method of estimation is quite effective. On the other hand, when the correlation is negative, Product method of estimation can be employed effectively. A mong the estimators mentioned above, the ratio estimator and its modifications are widely used for the estimation of the variance of the study variable. Estimation of population variance is considered by Isaki[10] where ratio and regression estimators are proposed. Prasad and Singh $[14\rceil$ have considered a ratio type estimator for estimation of population variance by improving Isaki[10] estimator with respect to bias and precision. Arcos et al.[4] have introduced another ratio type estimator, which has also improved the Isaki[10] estimator, which is almost unbiased and more precise than the other estimators.

Before discussing further about the traditional ratio type variance estimator, existing modified ratio type variance estimators and the proposed modified ratio type variance estimators, the notations to be used in this paper are described below:
N - Population size
On - Sample size
$\gamma=1 / n$
Y - Study variable
$X$ - Auxiliary variable
$\bar{X}, \bar{Y}-$ Population means
$\bar{x}, \bar{y}-$ Sample means
$\mathrm{S}_{\mathrm{y}}^{2}, \mathrm{~S}_{\mathrm{x}}^{2}-$ Population variances
$s_{y}^{2}, s_{x}^{2}-$ Sample variances
$C_{X}, C_{y}-$ Coefficient of variations
$\rho-$ Coefficient of correlation
$\mathrm{Q}_{1}$ - First (lower) quartile 
- $\mathrm{Q}_{3}$-Third (upper) quartile

Q $Q_{\mathrm{r}}$-Inter-quartile range

- $Q_{d}$-Semi-quartile range

$\mathrm{Q}_{\mathrm{a}}-$ Semi-quartile average

B $($.$) - Bias of the estimator$

- MSE(.) - Mean squared error of the estimator

- $\widehat{S}_{\mathrm{R}}^{2}$ - Traditional ratio type variance estimator of $\mathrm{S}_{\mathrm{y}}^{2}$

- $\hat{S}_{\mathrm{KCi}}^{2}$ - Existing modified ratio type variance estimator of $S_{\mathrm{v}}^{2}$

$\widehat{S}_{\mathrm{JGi}}^{2}-$ Proposed modified ratio type variance estimator of $S_{y}^{2}$

Isaki[10] suggested a ratio type variance estimator for the population variance $S_{\mathrm{y}}^{2}$ when the population variance $S_{\mathrm{x}}^{2}$ of the auxiliary variable $X$ is known together with its bias and mean squared error and are as given below:

$$
\begin{gathered}
\hat{S}_{\mathrm{R}}^{2}=\mathrm{s}_{\mathrm{y}}^{2} \frac{S_{\mathrm{x}}^{2}}{\mathrm{~s}_{\mathrm{x}}^{2}} \\
\mathrm{~B}\left(\widehat{\mathrm{S}}_{\mathrm{R}}^{2}\right)=\gamma S_{\mathrm{y}}^{2}\left[\left(\beta_{2(\mathrm{x})}\right)-\left(\lambda_{22}-1\right)\right] \\
\operatorname{MSE}\left(\widehat{S}_{\mathrm{R}}^{2}\right)=\gamma S_{\mathrm{y}}^{4}\left[\left(\beta_{2(\mathrm{y})}-1\right)+\left(\beta_{2(\mathrm{x})}-1\right)-2\left(\lambda_{22}-1\right)\right] \\
\text { where } \beta_{2(\mathrm{y})}=\frac{\mu_{40}}{\mu_{20}^{2}}, \beta_{2(\mathrm{x})}=\frac{\mu_{04}}{\mu_{02}^{2}}, \lambda_{22}=\frac{\mu_{22}}{\mu_{20} \mu_{02}} \text { and } \\
\mu_{\mathrm{rs}}=\frac{1}{\mathrm{~N}} \sum_{\mathrm{i}=1}^{\mathrm{N}}\left(\mathrm{y}_{\mathrm{i}}-\overline{\mathrm{Y}}\right)^{\mathrm{r}}\left(\mathrm{x}_{\mathrm{i}}-\overline{\mathrm{X}}\right)^{\mathrm{s}}
\end{gathered}
$$

The Ratio type variance estimator given in (1) is used to improve the precision of the estimate of the population variance compared to simple random sampling when there exists a positive correlation between $\mathrm{X}$ and $\mathrm{Y}$. Further improvements are also achieved on the classical ratio estimator by introducing a number of modified ratio estimators with the use of known parameters like Co-efficient of Variation, Co-efficient of Kurtosis. The problem of constructing efficient estimators for the population variance has been widely discussed by various authors such as Agarwal and Sithapit[1], Ahmed et al.[2], Al-Jararha and Al-Haj Ebrahem[3], Arcos et al.[4], Bhushan[5], Cochran[6], Das and Tripathi[7], Garcia and Cebrain[8], Gupta and Shabbir[9], Isaki[10], Kadilar and Cingi[11,12], Murthy[13], Prasad and Singh[14], Reddy[15], Singh and Chaudhary[16], Singh et al.[17,19], Upadhyaya and Singh[23] and Wolter[24].

Motivated by Singh et al.[18], Sisodia and Dwivedi[20], and Upadhyaya and Singh[22], Kadilar and Cingi[11] suggested four ratio type variance estimators using known values of Co-efficient of variation $C_{X}$ and Co-efficient of Kurtosis $\beta_{2(x)}$ of an auxiliary variable $X$ together with their biases and mean squared errors as given in the Table 1.

The existing modified ratio type variance estimators discussed above are biased but have minimum mean squared errors compared to the traditional ratio type variance estimator suggested by Isaki[10]. The list of estimators given in Table 1 uses the known values of the parameters like $S_{x}^{2}, C_{x}, \beta_{2}$ and their linear combinations. Subramani and Kumarapandiyan[21] used Quartiles and their functions of the auxiliary variable like Inter-quartile range, Semi-quartile range and Semi-quartile average to improve the ratio estimators in estimation of population mean. Further we know that the value of quartiles and their functions are unaffected by the extreme values or the presence of outliers in the population values unlike the other parameters like the variance, coefficient of variation and coefficient of kurtosis. The points discussed above have motivated us to introduce a modified ratio type variance estimators using the known values of the quartiles and their functions of the auxiliary variable.

Now briefly we will discuss about quartiles and its functions. The median divides the data into two equal sets. The first (lower) quartile is the middle value of the first set, where $25 \%$ of the values are smaller than $Q_{1}$ and $75 \%$ are larger. The third (upper) quartile is the middle value of the second set, where $75 \%$ of the values are smaller than the third quartile $Q_{3}$ and $25 \%$ are larger. It should be noted that the median will be denoted by the notation $Q_{2}$, the second quartile. The inter-quartile range is another range used as a measure of the spread. The difference between upper and lower quartiles, which is called as the inter-quartile range, also indicates the dispersion of a data set. The formula for inter-quartile range is:

$$
Q_{r}=\left(Q_{3}-Q_{1}\right)
$$

The semi-quartile range is another measure of spread. It is calculated as one half of the differences between the quartiles $Q_{3}$ and $Q_{1}$. The formula for semi-quartile range is:

$$
Q_{d}=\left(Q_{3}-Q_{1}\right) / 2
$$

\begin{tabular}{|c|c|c|}
\hline Estimator & Bias - $\mathbf{B}()$. & Mean squared error $\operatorname{MSE}()$. \\
\hline $\begin{array}{l}\hat{\mathrm{S}}_{\mathrm{KC} 1}^{2}=\mathrm{s}_{\mathrm{y}}^{2}\left[\frac{S_{\mathrm{x}}^{2}+\mathrm{C}_{\mathrm{x}}}{\mathrm{s}_{\mathrm{x}}^{2}+\mathrm{C}_{\mathrm{x}}}\right\rfloor \\
\text { Kadilar and Cingi[11] }\end{array}$ & $\gamma S_{y}^{2} A_{K C 1}\left[A_{K C 1}\left(\beta_{2(x)}-1\right)-\left(\lambda_{22}-1\right)\right]$ & $\gamma S_{\mathrm{y}}^{4}\left[\left(\beta_{2(\mathrm{y})}-1\right)+\mathrm{A}_{\mathrm{KC} 1}^{2}\left(\beta_{2(\mathrm{x})}-1\right)-2 \mathrm{~A}_{\mathrm{KC} 1}\left(\lambda_{22}-1\right)\right]$ \\
\hline $\begin{array}{c}\hat{\mathrm{S}}_{\mathrm{KC} 2}^{2}=\mathrm{s}_{\mathrm{y}}^{2}\left[\frac{\mathrm{S}_{\mathrm{x}}^{2}+\beta_{2(\mathrm{x})}}{\mathrm{s}_{\mathrm{x}}^{2}+\beta_{2(\mathrm{x})}}\right] \\
\text { Kadilar and Cingi[11] }\end{array}$ & $\gamma S_{y}^{2} A_{K C 2}\left[A_{K C 2}\left(\beta_{2(x)}-1\right)-\left(\lambda_{22}-1\right)\right]$ & $\gamma S_{\mathrm{y}}^{4}\left[\left(\beta_{2(\mathrm{y})}-1\right)+\mathrm{A}_{\mathrm{KC} 2}^{2}\left(\beta_{2(\mathrm{x})}-1\right)-2 \mathrm{~A}_{\mathrm{KC} 2}\left(\lambda_{22}-1\right)\right]$ \\
\hline $\begin{array}{c}\widehat{S}_{\mathrm{KC} 3}^{2}=s_{\mathrm{y}}^{2}\left[\frac{S_{\mathrm{x}}^{2} \beta_{2(\mathrm{x})}+\mathrm{C}_{\mathrm{x}}}{\mathrm{s}_{\mathrm{x}}^{2} \beta_{2(\mathrm{x})}+\mathrm{C}_{\mathrm{x}}}\right] \\
\text { Kadilar and Cingi }[11]\end{array}$ & $\gamma S_{y}^{2} A_{K C 3}\left[A_{K C 3}\left(\beta_{2(x)}-1\right)-\left(\lambda_{22}-1\right)\right]$ & $\gamma S_{\mathrm{y}}^{4}\left[\left(\beta_{2(\mathrm{y})}-1\right)+\mathrm{A}_{\mathrm{KC} 3}^{2}\left(\beta_{2(\mathrm{x})}-1\right)-2 \mathrm{~A}_{\mathrm{KC} 3}\left(\lambda_{22}-1\right)\right]$ \\
\hline $\begin{array}{c}\hat{\mathrm{S}}_{\mathrm{KC} 4}^{2}=\mathrm{s}_{\mathrm{y}}^{2}\left[\frac{S_{\mathrm{x}}^{2} \mathrm{C}_{\mathrm{x}}+\beta_{2(\mathrm{x})}}{\mathrm{s}_{\mathrm{x}}^{2} \mathrm{C}_{\mathrm{x}}+\beta_{2(\mathrm{x})}}\right] \\
\text { Kadilar and Cingi[11] }\end{array}$ & $\gamma \mathrm{S}_{\mathrm{y}}^{2} \mathrm{~A}_{\mathrm{KC} 4}\left[\mathrm{~A}_{\mathrm{KC} 4}\left(\beta_{2(\mathrm{x})}-1\right)-\left(\lambda_{22}-1\right)\right]$ & $\gamma S_{y}^{4}\left[\left(\beta_{2(y)}-1\right)+A_{\mathrm{KC} 4}^{2}\left(\beta_{2(x)}-1\right)-2 A_{K C 4}\left(\lambda_{22}-1\right)\right]$ \\
\hline
\end{tabular}

Subramani and Kumarapandiyan $[21\rceil$ suggested another new measure called as Semi-quartile average denoted by the notation $Q_{a}$ and defined as:

$$
\mathrm{Q}_{\mathrm{a}}=\left(\mathrm{Q}_{3}+\mathrm{Q}_{1}\right) / 2
$$

Table 1. Existing Modified rat io type variance est imators with their biases and mean squared errors 
where $A_{K C 1}=\frac{s_{x}^{2}}{S_{x}^{2}+C_{x}}, A_{K C 2}=\frac{S_{x}^{2}}{S_{x}^{2}+\beta_{2(x)}}, A_{K C 3}=\frac{S_{x}^{2} \beta_{2(x)}}{S_{x}^{2} \beta_{2(x)}+C_{x}}$ and $A_{K C 4}=\frac{s_{x}^{2} C_{x}}{S_{x}^{2} C_{x}+\beta_{2(x)}}$

\section{Proposed Estimators Using Quartiles and Their Functions}

In this section we have suggested a class of modified ratio type variance estimators using the quartiles and their functions of the auxiliary variable like Inter-quartile range, Semi-quartile range and Semi-quartile average

The proposed class of modified ratio type variance estimators $\widehat{S}_{\mathrm{JGi}}^{2}, i=1,2, \ldots, 5$ for estimating the population variance $\mathrm{S}_{\mathrm{y}}^{2}$ together with the first degree of appro ximation, the biases and mean squared errors and the constants are given below:

Table 2. Proposed modified ratio type variance est imators with their biases and mean squared errors

\begin{tabular}{|c|c|c|}
\hline Estimator & Bias - $\mathbf{B}()$. & Mean squared error $\operatorname{MSE}()$. \\
\hline$\widehat{S}_{\mathrm{GG} 1}^{2}=s_{\mathrm{y}}^{2}\left\lfloor\frac{S_{\mathrm{x}}^{2}+Q_{1}}{s_{\mathrm{x}}^{2}+Q_{1}}\right\rfloor$ & $\gamma S_{\mathrm{y}}^{2} A_{\mathrm{JG} 1}\left[A_{\mathrm{JG} 1}\left(\beta_{2(\mathrm{x})}-1\right)-\left(\lambda_{22}-1\right)\right]$ & $\gamma S_{y}^{4}\left[\left(\beta_{2(y)}-1\right)+A_{\mathrm{JG} 1}^{2}\left(\beta_{2(\mathrm{x})}-1\right)-2 \mathrm{~A}_{\mathrm{JG} 1}\left(\lambda_{22}-1\right)\right]$ \\
\hline$\widehat{S}_{\mathrm{JG} 2}^{2}=s_{\mathrm{y}}^{2}\left[\frac{S_{\mathrm{x}}^{2}+Q_{3}}{s_{\mathrm{x}}^{2}+Q_{3}}\right]$ & $\gamma \mathrm{S}_{\mathrm{y}}^{2} \mathrm{~A}_{\mathrm{JG} 2}\left[\mathrm{~A}_{\mathrm{JG} 2}\left(\beta_{2(\mathrm{x})}-1\right)-\left(\lambda_{22}-1\right)\right]$ & $\gamma S_{y}^{4}\left[\left(\beta_{2(y)}-1\right)+A_{\mathrm{JG} 2}^{2}\left(\beta_{2(x)}-1\right)-2 A_{\mathrm{JG} 2}\left(\lambda_{22}-1\right)\right]$ \\
\hline$\widehat{\mathrm{S}}_{\mathrm{fG} 3}^{2}=\mathrm{s}_{\mathrm{y}}^{2}\left|\frac{S_{\mathrm{x}}^{2}+Q_{\mathrm{r}}}{\mathrm{s}_{\mathrm{x}}^{2}+Q_{\mathrm{r}}}\right|$ & $\gamma \mathrm{S}_{\mathrm{y}}^{2} \mathrm{~A}_{\mathrm{IG} 3}\left[\mathrm{~A}_{\mathrm{IG} 3}\left(\beta_{2(\mathrm{x})}-1\right)-\left(\lambda_{22}-1\right)\right]$ & $\gamma S_{y}^{4}\left[\left(\beta_{2(y)}-1\right)+A_{J G 3}^{2}\left(\beta_{2(x)}-1\right)-2 A_{I G 3}\left(\lambda_{22}-1\right)\right]$ \\
\hline$\hat{S}_{\mathrm{fG} 4}^{2}=s_{\mathrm{y}}^{2}\left[\frac{S_{\mathrm{x}}^{2}+Q_{\mathrm{d}}}{s_{\mathrm{x}}^{2}+Q_{\mathrm{d}}}\right]$ & $\gamma S_{y}^{2} A_{\mathrm{JG} 4}\left[A_{\mathrm{JG} 4}\left(\beta_{2(x)}-1\right)-\left(\lambda_{22}-1\right)\right]$ & $\gamma S_{y}^{4}\left[\left(\beta_{2(y)}-1\right)+A_{\mathrm{JG} 4}^{2}\left(\beta_{2(x)}-1\right)-2 A_{\mathrm{JG} 4}\left(\lambda_{22}-1\right)\right]$ \\
\hline$\hat{S}_{\mathrm{fG} 5}^{2}=\mathrm{s}_{\mathrm{y}}^{2}\left[\frac{S_{x}^{2}+Q_{a}}{s_{x}^{2}+Q_{a}}\right]$ & $\gamma \mathrm{S}_{\mathrm{y}}^{2} \mathrm{~A}_{\mathrm{JG} 5}\left[\mathrm{~A}_{\mathrm{JG} 5}\left(\beta_{2(\mathrm{x})}-1\right)-\left(\lambda_{22}-1\right)\right]$ & $\gamma S_{y}^{4}\left[\left(\beta_{2(y)}-1\right)+A_{\mathrm{JG} 5}^{2}\left(\beta_{2(x)}-1\right)-2 A_{\mathrm{JG} 5}\left(\lambda_{22}-1\right)\right]$ \\
\hline & $S_{x}^{2}-A_{x}=\frac{S_{x}^{2}}{x}$ & $\frac{S_{x}^{2}}{+Q_{r}}, A_{J G 4}=\frac{S_{x}^{2}}{S_{x}^{2}+Q_{d}}$ and $A_{J G 5}=\frac{S_{x}^{2}}{S_{x}^{2}+Q_{a}}$ \\
\hline
\end{tabular}

\section{Efficiency of the Proposed Estimators}

As we mentioned earlier the bias and mean squared error of the traditional ratio type variance estimator are given below:

$$
\begin{aligned}
\mathrm{B}\left(\widehat{S}_{\mathrm{R}}^{2}\right) & =\gamma S_{\mathrm{y}}^{2}\left[\left(\beta_{2(\mathrm{x})}-1\right)-\left(\lambda_{22}-1\right)\right] \\
\operatorname{MSE}\left(\widehat{S}_{\mathrm{R}}^{2}\right) & =\gamma S_{\mathrm{y}}^{4}\left[\left(\beta_{2(\mathrm{y})}-1\right)+\left(\beta_{2(\mathrm{x})}-1\right)-2\left(\lambda_{22}-1\right)\right]
\end{aligned}
$$

For want of space; for the sake of convenience to the readers and for the ease of comparisons, the biases and mean squared errors of the existing modified ratio type variance estimators given in Table 1 are represented in single class as given below:

$$
\begin{aligned}
& \mathrm{B}\left(\widehat{\mathrm{S}}_{\mathrm{KCi}}^{2}\right)=\gamma \mathrm{S}_{\mathrm{y}}^{2} \mathrm{~A}_{\mathrm{KCi}}\left[\mathrm{A}_{\mathrm{KCi}}\left(\beta_{2(\mathrm{x})}-1\right)-\left(\lambda_{22}-1\right)\right] ; \mathrm{i}=1,2,3 \text { and } 4 \\
& \operatorname{MSE}\left(\widehat{S}_{\mathrm{KCi}}^{2}\right)=\gamma S_{\mathrm{y}}^{4}\left[\left(\beta_{2(\mathrm{y})}-1\right)+A_{\mathrm{KCi}}^{2}\left(\beta_{2(\mathrm{x})}-1\right)-2 \mathrm{~A}_{\mathrm{KCi}}\left(\lambda_{22}-1\right)\right] ; \mathrm{i}=1,2,3 \text { and } 4 \\
& \text { where } A_{K C 1}=\frac{s_{x}^{2}}{s_{x}^{2}+C_{x}}, A_{K C 2}=\frac{s_{x}^{2}}{s_{x}^{2}+\beta_{2(x)}}, A_{K C 3}=\frac{s_{x}^{2} \beta_{2(x)}}{s_{x}^{2} \beta_{2(x)}+C_{x}} \text { and } A_{K C 4}=\frac{s_{x}^{2} C_{x}}{s_{x}^{2} C_{x}+\beta_{2(x)}}
\end{aligned}
$$

In the same way, the biases and mean squared errors of the proposed modified ratio type variance estimators given in Table 2 are represented in a single class as given below:

$$
\begin{array}{r}
B\left(\widehat{S}_{J G j}^{2}\right)=\gamma S_{y}^{2} A_{J G j}\left[A_{J G j}\left(\beta_{2(x)}-1\right)-\left(\lambda_{22}-1\right)\right] ; j=1,2,3,4 \text { and } 5 \\
\operatorname{MSE}\left(\widehat{S}_{J G j}^{2}\right)=\gamma S_{y}^{4}\left[\left(\beta_{2(y)}-1\right)+A_{J G j}^{2}\left(\beta_{2}(x)-1\right)-2 A_{J G j}\left(\lambda_{22}-1\right)\right] ; j=1,2,3,4 \text { and } 5 \\
\text { where } A_{J G 1}=\frac{s_{x}^{2}}{s_{x}^{2}+Q_{1}}, A_{J G 2}=\frac{s_{x}^{2}}{s_{x}^{2}+Q_{3}}, A_{J G 3}=\frac{s_{x}^{2}}{s_{x}^{2}+Q_{r}}, A_{J G 4}=\frac{s_{x}^{2}}{s_{x}^{2}+Q_{d}} \text { and } A_{J G 5}=\frac{s_{x}^{2}}{s_{x}^{2}+Q_{a}}
\end{array}
$$

From the expressions given in (6) and (10) we have derived the condition for which the proposed estimators $\widehat{S}_{\text {JGj }}^{2} ; j=$ $1,2,3,4$ and 5 are more efficient than the traditional ratio type variance estimator and it is given below:

$$
\operatorname{MSE}\left(\widehat{\mathrm{S}}_{\mathrm{JGj}}^{2}\right)<\operatorname{MSE}\left(\widehat{\mathrm{S}}_{\mathrm{R}}^{2}\right) \text { if } \lambda>1+\frac{\left(\mathrm{A}_{\mathrm{JGj}}+1\right)\left(\beta_{2(\mathrm{x})}-1\right)}{2} ; \mathrm{j}=1,2,3,4 \text { and } 5
$$

From the expressions given in (8) and (10) we have derived the conditions for which the proposed estimators $\widehat{S}_{\text {Jjj }}^{2} ; \mathrm{j}=$ $1,2,3,4$ and 5 are more efficient than the existing modified ratio type variance estimators given in Table $1, \widehat{\mathrm{S}}_{\mathrm{KC}}^{2} ; \mathrm{i}=$ $1,2,3$ and 4 and are given below:

$$
\operatorname{MSE}\left(\widehat{S}_{\mathrm{JGj}}^{2}\right)<\operatorname{MSE}\left(\widehat{\mathrm{S}}_{\mathrm{KCi}}^{2}\right) \text { if } \lambda>1+\frac{\left(\mathrm{A}_{\mathrm{JGj}}+\mathrm{A}_{\mathrm{i}}\right)\left(\beta_{2(\mathrm{x})}-1\right)}{2} ; \mathrm{i}=1,2,3 \text { and } 4 ; \mathrm{j}=1,2,3,4 \text { and } 5
$$




\section{Numerical Study}

The performance of the proposed modified ratio type variance estimators are assessed with that of traditional ratio type estimator and existing modified ratio type variance estimators listed in Table 1 for certain natural populations. The populations 1 and 2 are the real data set taken from the Report on Waste 2004 drew up by the Italian bureau for the environment protection-APAT. Data and reports are available in the website http://www.os servatorionazionalerifiuti.it[25]. In the data set, for each of the Italian provinces, three variables are considered: the total amount (tons) of recyclable-waste collection in Italy in 2003 (Y), the total amount of recyclable-waste collection in Italy in $2002\left(\mathrm{X}_{1}\right)$ and the number of inhabitants in $2003\left(\mathrm{X}_{2}\right)$. The population 3 is taken fromMurthy[13] given in page 228 and population 4 is taken from $\mathrm{Singh}$ and Chaudhary[16] given in page 108. The population parameters and the constants computed from the above populations are given below:

Table 3. Parameters and Constants of the Populations

\begin{tabular}{|c|c|c|c|c|}
\hline Parameters & Population 1 & Population 2 & Population 3 & Population 4 \\
\hline $\mathrm{N}$ & 103 & 103 & 80 & 70 \\
\hline $\mathrm{n}$ & 40 & 40 & 20 & 25 \\
\hline$\overline{\mathrm{Y}}$ & 626.2123 & 62.6212 & 51.8264 & 96.7000 \\
\hline$\overline{\mathrm{X}}$ & 557.1909 & 556.5541 & 11.2646 & 175.2671 \\
\hline$\rho$ & 0.9936 & 0.7298 & 0.9413 & 0.7293 \\
\hline $\mathrm{S}_{\mathrm{y}}$ & 913.5498 & 91.3549 & 18.3569 & 60.7140 \\
\hline $\mathrm{C}_{\mathrm{y}}$ & 1.4588 & 1.4588 & 0.3542 & 0.6254 \\
\hline$S_{x}$ & 818.1117 & 610.1643 & 8.4563 & 140.8572 \\
\hline $\mathrm{C}_{\mathrm{x}}$ & 1.4683 & 1.0963 & 0.7507 & 0.8037 \\
\hline$\beta_{2(\mathrm{x})}$ & 37.3216 & 17.8738 & 2.8664 & 7.0952 \\
\hline$\beta_{2(y)}$ & 37.1279 & 37.1279 & 2.2667 & 4.7596 \\
\hline$\lambda_{22}$ & 37.2055 & 17.2220 & 2.2209 & 4.6038 \\
\hline $\mathrm{Q}_{1}$ & 142.9950 & 259.3830 & 5.1500 & 80.1500 \\
\hline $\mathrm{Q}_{3}$ & 665.6250 & 628.0235 & 16.9750 & 225.0250 \\
\hline $\mathrm{Q}_{\mathrm{r}}$ & 522.6300 & 368.6405 & 11.8250 & 144.8750 \\
\hline$Q_{d}$ & 261.3150 & 184.3293 & 5.9125 & 72.4375 \\
\hline$Q_{a}$ & 404.3100 & 443.7033 & 11.0625 & 152.5875 \\
\hline $\mathrm{A}_{\mathrm{KC} 1}$ & 0.9999 & 0.9999 & 0.9896 & 0.9999 \\
\hline $\mathrm{A}_{\mathrm{KC} 2}$ & 0.9999 & 0.9999 & 0.9615 & 0.9996 \\
\hline $\mathrm{A}_{\mathrm{KC} 3}$ & 0.9999 & 0.9999 & 0.9964 & 0.9999 \\
\hline $\mathrm{A}_{\mathrm{KC} 4}$ & 0.9999 & 0.9999 & 0.9493 & 0.9996 \\
\hline$A_{\mathrm{JG} 1}$ & 0.9997 & 0.9994 & 0.9328 & 0.9960 \\
\hline $\mathrm{A}_{\mathrm{JG} 2}$ & 0.9990 & 0.9983 & 0.8082 & 0.9888 \\
\hline $\mathrm{A}_{\mathrm{JG} 3}$ & 0.9992 & 0.9990 & 0.8581 & 0.9928 \\
\hline $\mathrm{A}_{\mathrm{JG} 4}$ & 0.9996 & 0.9995 & 0.9236 & 0.9964 \\
\hline $\mathrm{A}_{\mathrm{JG} 5}$ & 0.9993 & 0.9988 & 0.8660 & 0.9924 \\
\hline
\end{tabular}

The biases and mean squared errors of the existing and proposed modified ratio type variance estimators for the populations given above are given in the following Tables: 
Table 4. Biases of the existing and proposed modified rat io type variance est imators

\begin{tabular}{|l|c|c|c|c|}
\hline \multirow{2}{*}{ Estimator } & \multicolumn{4}{c|}{ Bias B(.) } \\
\cline { 2 - 5 } & Population 1 & Population 2 & Population 3 & Population 4 \\
\hline$\widehat{\mathrm{S}}_{\mathrm{R}}^{2}$ Isaki[10] & 2422.3488 & 135.9935 & 10.8762 & 364.4211 \\
\hline$\widehat{\mathrm{S}}_{\mathrm{KC} 1}^{2}$ Kadilar and Cingi[11] & 2420.6810 & 135.9827 & 10.4399 & 364.3702 \\
\hline$\widehat{\mathrm{S}}_{\mathrm{KC} 2}^{2}$ Kadilar and Cingi[11] & 2379.9609 & 135.8179 & 9.2918 & 363.9722 \\
\hline$\widehat{\mathrm{S}}_{\mathrm{KC} 3}^{2}$ Kadilar and Cingi[11] & 2422.3041 & 135.9929 & 10.7222 & 364.4139 \\
\hline$\widehat{\mathrm{S}}_{\mathrm{KC} 4}^{2}$ Kadilar and Cingi[11] & 2393.4791 & 135.8334 & 8.8117 & 363.8627 \\
\hline$\widehat{\mathrm{S}}_{\mathrm{JG} 1}^{2}$ Proposed Estimator & 2259.9938 & 133.4494 & 8.1749 & 359.3822 \\
\hline$\widehat{\mathrm{S}}_{\mathrm{JG} 2}^{2}$ Proposed Estimator & 1667.7818 & 129.8456 & 3.9142 & 350.4482 \\
\hline$\widehat{\mathrm{S}}_{\mathrm{JG} 3}^{2}$ Proposed Estimator & 1829.6315 & 132.3799 & 5.5038 & 355.3634 \\
\hline$\widehat{\mathrm{S}}_{\mathrm{JG} 4}^{2}$ Proposed Estimator & 2125.7591 & 134.1848 & 7.8275 & 359.8641 \\
\hline$\widehat{\mathrm{S}}_{\mathrm{JG} 5}^{2}$ Proposed Estimator & 1963.6570 & 131.6458 & 5.7705 & 354.8875 \\
\hline
\end{tabular}

Table 5. Mean squared errors of the existing and proposed modified rat io type variance est imators

\begin{tabular}{|l|c|c|c|c|}
\hline \multirow{2}{*}{ Estimator } & \multicolumn{4}{|c|}{ Mean Squared Error MSE(.) } \\
\cline { 2 - 5 } & Population 1 & Population 2 & Population 3 & Population 4 \\
\hline$\widehat{\mathrm{S}}_{\mathrm{R}}^{2}$ Isaki[10] & 670393270 & 35796612 & 3925.1627 & 1415946 \\
\hline$\widehat{\mathrm{S}}_{\mathrm{KC} 1}^{2}$ Kadilar and Cingi[11] & 670384403 & 35796605 & 3850.1552 & 1415839 \\
\hline$\widehat{\mathrm{S}}_{\mathrm{KC} 2}^{2}$ Kadilar and Cingi[11] & 670169790 & 35796503 & 3658.4051 & 1414994 \\
\hline$\widehat{\mathrm{S}}_{\mathrm{KC} 3}^{2}$ Kadilar and Cingi[11] & 670393032 & 35796611 & 3898.5560 & 1415931 \\
\hline$\widehat{S}_{\mathrm{KC} 4}^{2}$ Kadilar and Cingi[11] & 670240637 & 35796512 & 3580.8342 & 1414762 \\
\hline$\widehat{\mathrm{S}}_{\mathrm{JG} 1}^{2}$ Proposed Estimat or & 669558483 & 35795045 & 3480.5516 & 1405276 \\
\hline$\widehat{\mathrm{S}}_{\mathrm{IG} 2}^{2}$ Proposed Estimator & 667000531 & 35792872 & 2908.9467 & 1386468 \\
\hline$\widehat{\mathrm{S}}_{\mathrm{IG} 3}^{2}$ Proposed Estimator & 667623576 & 35794395 & 3098.4067 & 1396798 \\
\hline$\widehat{\mathrm{S}}_{\mathrm{S} 4}^{2}$ Proposed Estimator & 668911625 & 35795495 & 3427.1850 & 1406294 \\
\hline$\widehat{\mathrm{S}}_{\mathrm{J} 5}^{2}$ Proposed Estimator & 668182833 & 35793951 & 3133.3256 & 1395796 \\
\hline
\end{tabular}

From the values of Table 4, it is observed that the biases of the proposed modified ratio type variance estimators are less than the biases of the traditional and existing modified ratio type variance estimators. Similarly from the values of Table 5 , it is observed that the mean squared errors of the proposed modified ratio type variance estimators are less than the mean squared errors of the traditional and existing modified ratio type variance estimators.

\section{Conclusions}

Estimating the finite population variance has great significance in various fields such as Industry, Agriculture, Medical and Biological sciences, etc. In this paper we have proposed a class of modified ratio type variance estimators using the quartiles and their functions of the auxiliary variable like Inter-quartile range, Semi-quartile range and Semi-quartile average. The biases and mean squared errors of the proposed modified ratio type variance estimators are obtained and compared with that of traditional ratio type variance estimator and existing modified ratio type variance estimators. Further we have derived the conditions for which the proposed estimators are more efficient than the traditional and existing estimators. We have also assessed the performance of the proposed estimators for some known natural populations. It is observed that the biases and mean squared errors of the proposed estimators are less than the biases and mean squared errors of the traditional and existing modified estimators for certain known populations. Hence we strongly recommend that the proposed modified ratio type variance estimator may be preferred over the traditional ratio type variance estimator and existing modified ratio type variance estimators for the use of practical applications.

\section{ACKNOWLEDGEMENTS}

The second author wishes to acknowledge his sincere thanks to the Vice Chancellor, Pondicherry University for the financial support to carry out this research work through the University Fellowship.

\section{REFERENCES}

[1] Agarwal, M.C. and Sithapit, A.B. (1995). Unbiased ratio type estimation, Statistics and Probability Letters 25, 361-364

[2] Ahmed, M.S., Raman, M.S. and Hossain, M.I. (2000). Some competitive estimators of finite population variance Multivariate Auxiliary Information, Information and Management Sciences, Volume11 (1), 49-54 
[3] Al-Jararha, J. and Al-Haj Ebrahem, M. (2012). A ratio estimator under general sampling design, Austrian Journal of Statistics, Volume 41(2), 105-115

[4] Arcos, A., Rueda, M., Martinez, M.D., Gonzalez, S., Roman, Y. (2005). Incorporating the auxiliary information available in variance estimation, Applied Mathematics and Computation 160, 387-399

[5] Bhushan, S. (2012). Some efficient sampling strategies based on ratio type, estimator, Electronic Journal of Applied Statistical Analy sis, Volume 5(1), 74-88

[6] Cochran, W. G. (1977). Sampling techniques, Third Edition, Wiley Eastern Limited

[7] Das, A.K. and Tripathi, T.P. (1978). Use of auxiliary information in estimating the finite population variance, Sankhya 40, 139-148

[8] Garcia, M.K. and Cebrain, A.A. (1997). Variance estimation using auxiliary information: An almost unbiased multivariate ratio estimator, Metrika 45, 171-178

[9] Gupta, S. and Shabbir, J. (2008). Variance estimation in simple random sampling using auxiliary information, Hacettepe Journal of Mathematics and Statistics, Volume 37, 57-67

[10] Isaki, C.T. (1983). Variance estimation using auxiliary information, Journal of the American Statistical Association $78,117-123$

[11] Kadilar, C. and Cingi, H. (2006). Improvement in variance estimation using auxiliary information, Hacettepe Journal of Mathematics and Statistics Volume 35 (1), 111-115

[12] Kadilar, C. and Cingi, H. (2006). Ratio estimators for population variance in simple and stratified sampling, Applied Mathematics and Computation 173, 1047-1058

[13] Murthy, M.N. (1967). Sampling theory and methods, Statistical Publishing So ciety, Calcutta, India

[14] Prasad, B. and Singh, H.P. (1990). Some improved ratio type estimators of finite population variance in sample surveys, Communication in Statistics: Theory and Methods 19, 1127-1139
[15] Reddy, V.N. (1974). On a transformed ratio method of estimation, Sankhya, Volume C36, 59-70

[16] Singh, D. and Chaudhary, F.S. (1986). Theory and analy sis of sample survey designs, New Age International Publisher

[17] Singh, H.P., Chandra, P. and Singh, S. (2003). Variance estimation using multi-auxiliary information for random non-response in survey sampling, STATISTICA, anno LXIII, n. $1,23-40$

[18] Singh, H.P., Tailor, R., Tailor, R. and Kakran, M.S. (2004). An improved estimator of population mean using power transformation, Journal of the Indian Society of Agricultural Statistics 58(2), 223-230

[19] Singh, H.P., Upadhyaya, U.D. and Namjoshi, U.D. (1988). Estimation of finite population variance, Current Science 57, 1331-1334

[20] Sisodia, B.V.S. and Dwivedi, V.K. (1981). A modified ratio estimator using coefficient of variation of auxiliary variable, Journal of the Indian Society of Agricultural Statistics 33(1), 13-18

[21] Subramani, J. and Kumarapandiyan, G. (2012). Modified ratio estimators for population mean using function of quartiles of auxiliary variable, Bonfring International Journal of Industrial Engineering and Management Science, Vol. 2(2), 19-23

[22] Upadhy ay a, L.N. and Singh, H.P. (1999). Use of transformed auxiliary variable in estimating the finite population mean, Biometrical Journal 41 (5), 627-636

[23] Upadhyaya, L. N. and Singh, H. P. (2006). Almost unbiased ratio and product-type estimators of finite population variance in sample surveys, Statistics in Transition 7 (5), 1087-1096

[24] Wolter, K.M. (1985). Introduction to Variance Estimation, Springer-Verlag

[25] http://www.osservatorionazionalerifiuti.it/ElencoDocPub.asp ?A_TipoDoc $=6$ 